\title{
Structural Stability, Electronic Structure and Mechanical Properties of Li-N-H System
}

\author{
Ratnavelu Rajeswarapalanichamy • Manoharan Santhosh • Ganesapandian Sudhapriyanga • \\ Shanmugam Kanagaprabha $\cdot$ Kombaih Iyakutti
}

Received: 10 July 2014/Revised: 24 September 2014/Published online: 14 February 2015

(c) The Chinese Society for Metals and Springer-Verlag Berlin Heidelberg 2015

\begin{abstract}
Ab}$ initio calculations are performed to investigate the ground state properties, structural phase transition, electronic structure and mechanical properties of lithium nitride $\left(\mathrm{Li}_{3} \mathrm{~N}\right)$, lithium imide $\left(\mathrm{Li}_{2} \mathrm{NH}\right)$ and lithium amide $\left(\mathrm{LiNH}_{2}\right)$. The computed ground state properties like equilibrium lattice constant, cell volume, valence electron density, cohesive energy, bulk modulus and its derivatives are in good agreement with available experimental data. The structural phase transitions from $\alpha-\mathrm{P} 6 / \mathrm{mmm}$ to $\beta$-P6 $3 / \mathrm{mmc}$ phase at a pressure of $17.5 \mathrm{GPa}$ in $\mathrm{Li}_{3} \mathrm{~N}$ and cubic $(\mathrm{Fm} 3 \mathrm{~m})$ to hexagonal $\left(\mathrm{P}_{3} /\right.$ mmc) phase at a pressure of $102 \mathrm{GPa}$ in lithium imide $\left(\mathrm{Li}_{2} \mathrm{NH}\right)$ are observed. A new high pressure hexagonal $\left(\mathrm{P}_{3} / \mathrm{mmc}\right)$ phase is predicted for $\mathrm{Li}_{2} \mathrm{NH}$. Electronic structure reveals that $\mathrm{Li}_{3} \mathrm{~N}$ and $\mathrm{LiNH}_{2}$ are semiconductors, whereas $\mathrm{Li}_{2} \mathrm{NH}$ is an insulator. The calculated elastic constants indicate that these materials are mechanically stable at ambient condition.
\end{abstract}

\section{KEY WORDS: Ab initio calculations; Crystal structure; Phase transition; Electronic structure; Mechanical} properties

\section{Introduction}

Lithium nitride is an unusual ionic conductor with several interesting properties and potential applications [1-6]. $\mathrm{Li}_{3} \mathrm{~N}$ crystallizes in hexagonal structure with the space group P6/mmm ( $\alpha$-phase) [7-12]. The existence of high pressure $\beta$-phase was confirmed by experiments, and their

Available online at http://link.springer.com/journal/40195

R. Rajeswarapalanichamy $(\bowtie) \cdot$ M. Santhosh ·

G. Sudhapriyanga

Department of Physics, N.M.S.S.V.N College, Madurai 625019,

Tamilnadu, India

e-mail: rajeswarapalanichamy@gmail.com

S. Kanagaprabha

Department of Physics, Kamaraj College, Tuticorin 628003 ,

Tamilnadu, India

K. Iyakutti

Department of Physics and Nanotechnology, SRM University,

Chennai 603203, Tamilnadu, India behavior at high pressure was studied [7, 13-15]. Hossain et al. [16] studied the elastic properties of $\alpha$ - and $\beta$-phases of $\mathrm{Li}_{3} \mathrm{~N}$ by means of first principles calculations. The interaction between $\mathrm{LiNH}_{2}$ and $\mathrm{LiH}$ was investigated by Chen et al. [17] and noticed that hydrogen can be reversibly stored in lithium nitride. Lithium imide $\left(\mathrm{Li}_{2} \mathrm{NH}\right)$ is a potentially important material for hydrogen storage. Safe storage materials for hydrogen are necessary for the manufacture of practical hydrogen-based energy sources. $\mathrm{Li}_{2} \mathrm{NH}$ was shown to be able to absorb $6.5 \mathrm{wt} \%$ of hydrogen. Ohoyama et al. [18] performed neutron powder diffraction experiments on $\mathrm{Li}_{2} \mathrm{NH}$ and proposed a crystal structure with face-centered cubic (fcc) symmetry (space group F4-3m). Magyari-Kope et al. [19] predicted orthorhombic structure (Pnma) as the stable structure for $\mathrm{Li}_{2} \mathrm{NH}$. Noritake et al. [20] performed X-ray powder diffraction experiments and suggested fcc structure (space group $\mathrm{Fm}-3 \mathrm{~m}$ ) for $\mathrm{Li}_{2} \mathrm{NH}$. Mueller and Ceder [21] proposed layered triclinic (P-1) and orthorhombic (Pbca) phases and concluded that orthorhombic $(\mathrm{Pbca})$ structure is more stable than triclinic (P-1) structure. Tsumuraya et al. 
[22] investigated orthorhombic (Ima2), orthorhombic ( $\mathrm{Pb}$ ca), orthorhombic (Pnma) and layered triclinic (P-1) structures for $\mathrm{Li}_{2} \mathrm{NH}$. Wolverton et al. [23] found a low energy orthorhombic Pnma structure for $\mathrm{Li}_{2} \mathrm{NH}$ at $0 \mathrm{~K}$. Crivello et al. [24] found that the orthorhombic (Pnma) structure is more stable than the cubic (F4-3m) structure at $0 \mathrm{~K}$. Miwa et al. [25] investigated hydrogen storage capacity of lithium amide $\left(\mathrm{LiNH}_{2}\right)$. Herbst and Hector Jr. [26] performed $\mathrm{Li}$ amide/Li imide hydrogen storage reaction and proposed a crystal structure with tetragonal (I4) phase for $\mathrm{LiNH}_{2}$. Lin et al. [27] investigated the influence of vacancy, impurity vacancy complex in the kinetics of $\mathrm{LiNH}_{2}$ complex hydrides using the first principles calculations. From the above mentioned literatures, it is observed that there are some contradictions in the structural stability of lithium imide under normal and high pressures. This motivated us to investigate the structural stability, electronic and elastic properties of $\mathrm{Li}_{2} \mathrm{NH}$. To the best of our knowledge, the elastic properties of $\mathrm{Li}_{3} \mathrm{~N}$, lithium imide $\mathrm{Li}_{2} \mathrm{NH}$ and lithium amide $\mathrm{LiNH}_{2}$ under normal and high pressures are not yet reported. In this paper, the structural stability, electronic structure and elastic properties are analyzed using the first principles calculations based on density functional theory.

\section{Theoretical Framework}

The ab initio calculations are performed using density functional theory within generalized gradient approximation (GGA) [28, 29] as implemented in the VASP code [30, 31]. The interaction between the ion and electron is described by the projector augmented wave method [32]. Ground state geometries are determined by minimizing stresses and Hellman-Feynman forces using the conjugategradient algorithm with force convergence less than $10^{-3} \mathrm{eV} / \AA$. The Kohn-Sham orbitals are expanded using the plane wave energy cutoff of $400 \mathrm{eV}$ [33]. The Brillouin zone integrations are carried out using the Monkhorst-Pack K-point mesh [34] with a grid size of $12 \times 12 \times 12$ for total energy calculation. The electronic configuration of $\mathrm{Li}$, $\mathrm{N}$ and $\mathrm{H}$ atoms is $\mathrm{Li} 1 s^{2} 2 s^{1}, \mathrm{~N} 2 s^{2}, \mathrm{~N} 2 p^{3}$ and $\mathrm{H} 1 s^{1}$, respectively.

\section{Results and Discussion}

\subsection{Ground State Properties of $\mathrm{Li}_{3} \mathrm{~N}, \mathrm{Li}_{2} \mathrm{NH}$ and $\mathrm{LiNH}_{2}$}

The lattice parameters are optimized for $\mathrm{Li}_{3} \mathrm{~N}$ with hexagonal $\alpha$ - $(\mathrm{P} 6 / \mathrm{mmm})$ and $\beta$-phases $\left(\mathrm{P}_{3} / \mathrm{mmc}\right)$. For $\mathrm{Li}_{2} \mathrm{NH}$, eight potential structures have been considered. They include three cubic structures with space group Fm-3m, $\mathrm{Pm} 3 \mathrm{~m}, \mathrm{~F} 4-3 \mathrm{~m}$, hexagonal structure with space group $\mathrm{P}_{3} / \mathrm{mmc}$, three orthorhombic structures with space group $\mathrm{Ima}_{2}, \mathrm{Pbca}$, Pnma and triclinic structure with space group P-1. The lattice constants are optimized for $\mathrm{LiNH}_{2}$ with tetragonal structure (space group I-4).

The total energy calculations are carried out for $\mathrm{Li}_{3} \mathrm{~N}$, $\mathrm{Li}_{2} \mathrm{NH}$ and $\mathrm{LiNH}_{2}$ with various possible structures for various volumes. The volume corresponding to the minimum energy is the equilibrium volume $V_{0}$. These data are then fitted to the universal second-order Birch-Murnaghnan equation of state [35] to determine the bulk modulus $B_{0}$ and its first derivative at normal pressure. The cohesive energy $\left(E_{\mathrm{coh}}\right)$ of a solid is the difference between the total energy per atom of the bulk material at ambient condition and the atomic energies of the atoms belonging to the unit cell of the material. The calculated ground state properties like lattice constants $a, b$ and $c(\AA)$, cell volume $V_{0}\left(\AA^{3}\right)$, valence electron density $\rho$ (electrons $\left./ \AA^{3}\right)$, cohesive energy $E_{\text {coh }}(\mathrm{eV})$, bulk modulus $B_{0}(\mathrm{GPa})$ and its derivatives $B_{0}^{\prime}$ for $\mathrm{Li}_{3} \mathrm{~N}, \mathrm{Li}_{2} \mathrm{NH}$ and $\mathrm{LiNH}_{2}$ are listed in Tables 1 and 2, respectively, along with the experimental and other available theoretical results $[7,14,16,18-22,25,27,36-38]$. The optimized lattice parameter for cubic $\mathrm{Li}_{2} \mathrm{NH}(\mathrm{Fm} 3 \mathrm{~m})$ is found to be $a_{0}=5.045 \AA$. This is in good agreement with the experimental value $a_{0}=5.047 \AA$ [20]. The calculated lattice constants are in good agreement with the experimental results $[18-22,38]$ and previous theoretical results [7, 14, 16, 25, 27, 36, 37]. The cohesive energies of these materials are observed to be higher than those of the host elements. It is also observed that $\alpha-\mathrm{Li}_{3} \mathrm{~N}, \mathrm{Li}_{2} \mathrm{NH}\left(\mathrm{P}_{3} / \mathrm{mmc}\right)$ and $\mathrm{LiNH}_{2}$ (I-4) are found to be the more stable owing to their highest cohesive energy values. This suggests that these materials can be easily synthesized at ambient condition.

\subsection{Structural Phase Transition of $\mathrm{Li}_{3} \mathrm{~N}$ and $\mathrm{Li}_{2} \mathrm{NH}$}

The total energy $\left(E_{\mathrm{tot}}\right)$ is calculated for hexagonal $\alpha$ - and $\beta$ phases of $\mathrm{Li}_{3} \mathrm{~N}$ and various phases considered for $\mathrm{Li}_{2} \mathrm{NH}$ as a function of pressure $(P)$. It is found that $\mathrm{Li}_{3} \mathrm{~N}$ is more stable in $\alpha$-phase at normal pressure. On further increasing the pressure, it undergoes a structural phase transition from $\alpha$ - to $\beta$-phase, whereas $\mathrm{Li}_{2} \mathrm{NH}$ is stable in cubic $(\mathrm{Fm}-3 \mathrm{~m})$ phase at normal pressure and a cubic (Fm-3m) to hexagonal $\left(\mathrm{P}_{3} / \mathrm{mmc}\right)$ phase transition is observed under high pressure. The enthalpy $(H)$ is calculated using the formula $H=E_{\mathrm{tot}}+P V$,

where $V$ is the volume of lattice. For $\mathrm{Li}_{3} \mathrm{~N}$ and $\mathrm{Li}_{2} \mathrm{NH}$, enthalpies as a function of pressure and their plots are given in Fig. 1. A structural phase transition from $\alpha$ - to $\beta$-phase is observed at a pressure of $17.5 \mathrm{GPa}$ in $\mathrm{Li}_{3} \mathrm{~N}$ which is in 
agreement with the Refs. [7, 13-15], and cubic-Fm3m to hexagonal- $\mathrm{P}_{3} / \mathrm{mmc}$ phase transition is predicted at a pressure of $102 \mathrm{GPa}$ in $\mathrm{Li}_{2} \mathrm{NH}$. A new high pressure hexagonal phase with space group $\mathrm{P}_{3} / \mathrm{mmc}$ is observed in $\mathrm{Li}_{2} \mathrm{NH}$.

\subsection{Electronic Structure}

\subsection{1 $\mathrm{Li}_{3} \mathrm{~N}$}

The energy band structure and total density of states (DOSs) of $\mathrm{Li}_{3} \mathrm{~N}$ in $\alpha$-phase is computed, along the symmetry directions $\mathrm{G}-\mathrm{K}-\mathrm{M}-\mathrm{G}-\mathrm{A}-\mathrm{L}-\mathrm{H}-\mathrm{A}$ at ambient condition. The electronic band structure and DOS of $\alpha-\mathrm{Li}_{3} \mathrm{~N}$ are given in Fig. 2. It is observed that lithium nitride has four valence bands corresponding to eight valence electrons which comes from $2 s^{1}$ state electron of $\mathrm{Li}$ atom and $2 s^{2} 2 p^{3}$ state electrons of $\mathrm{N}$ atom. The low lying band, in the energy range from -10 to $-12 \mathrm{eV}$, is mainly due to $\mathrm{N}-2 \mathrm{~s} \mathrm{~s}-$ tate. There is a gap of about $\sim 8 \mathrm{eV}$ between the band due to $\mathrm{N}-2 s$ state and the bottom of the other valence bands. The other valence bands are mainly due to $\mathrm{N}-2 p$ and $\mathrm{Li}$ $s$ states, indicating a strong covalent interaction between the lithium and nitrogen atoms. Above the Fermi level, empty conduction bands are present with a mixed $s$ and $p$ states of $\mathrm{Li}$ and $\mathrm{N}$ atoms. At normal pressure, the band gap of $\mathrm{Li}_{3} \mathrm{~N}(1.8 \mathrm{eV})$ is indirect with top of the valence band in A point and the bottom of the conduction band in $\mathrm{G}$ point, which confirms that $\mathrm{Li}_{3} \mathrm{~N}$ is a wide band gap semiconductor at normal pressure. From the DOS histogram (Fig. 2b), it is found that the peak in the region around $-10 \mathrm{eV}$ is due to the $s$-state electrons of the $\mathrm{N}$ atom. The peaks just below the Fermi level are mainly due to the $p$ state electrons of the nitrogen atom, along with a small contribution from the $s$-state electrons of the $\mathrm{Li}$ atom. The peaks above the Fermi level are due to the $s$ and $p$ states of $\mathrm{Li}$ and $\mathrm{N}$ atoms. The DOSs also confirms the semiconducting behavior of $\mathrm{Li}_{3} \mathrm{~N}$ at normal pressure. After 17.5 GPa, $\beta$-phase of $\mathrm{Li}_{3} \mathrm{~N}$ is more stable than $\alpha-\mathrm{Li}_{3} \mathrm{~N}$, so high pressure electronic band structure and DOSs are computed for $\beta-\mathrm{Li}_{3} \mathrm{~N}$, and the plots are given in Fig. 3a, b, respectively. It is found that at high pressure, the band gap is increased to $2.3 \mathrm{eV}$. Thus, at high pressure also, $\mathrm{Li}_{3} \mathrm{~N}$ is a wide band gap semiconductor.

\subsection{2 $\mathrm{Li}_{2} \mathrm{NH}$}

The electronic structure of $\mathrm{Li}_{2} \mathrm{NH}$ is investigated by computing the band structure and total DOSs in cubic Fm-3m phase, along the symmetry directions $\mathrm{L}-\mathrm{G}-\mathrm{X}-\mathrm{W}-\mathrm{L}-\mathrm{K}-\mathrm{G}$ at ambient condition, and the plots are given in Fig. 4. At normal pressure, the valence band minimum is located at the $\mathrm{L}$ point. It is observed that eight valence electrons of lithium imide form four valence bands. The band, which is 
Table 2 Calculated lattice parameters $a, b$ and $c(\AA)$, equilibrium volume $V_{0}\left(\AA^{3}\right)$, valence electron density $\rho$ (electrons $\left./ \AA^{3}\right)$, cohesive energy $E_{\text {coh }}(\mathrm{eV})$, bulk modulus $B_{0}(\mathrm{GPa})$ and its derivative $B_{0}^{\prime}$ for lithium imide $\left(\mathrm{Li}_{2} \mathrm{NH}\right)$ and litium amide $\left(\mathrm{LiNH}_{2}\right)$

\begin{tabular}{|c|c|c|c|c|c|c|c|c|c|}
\hline Materials & Space group & $a$ & $b$ & $c$ & $V_{0}$ & $\rho$ & $E_{\mathrm{coh}}$ & $B_{0}$ & $B_{0}^{\prime}$ \\
\hline \multirow[t]{8}{*}{$\mathrm{Li}_{2} \mathrm{NH}$} & $\mathrm{F} 43 \mathrm{~m}$ & $5.649,5.077^{\mathrm{a}}$ & & & 48.02 & 0.1665 & 0.7622 & 93.01 & 3.581 \\
\hline & Pnma & $7.704,7.733^{\mathrm{b}}$ & 3.75 & $5.074,3.60^{\mathrm{b}}, 4.872^{\mathrm{b}}$ & 42.36 & 0.1888 & 3.4819534 & 68.15 & 3.116 \\
\hline & $\mathrm{P}_{3} / \mathrm{mmc}$ & 3.657 & & 5.884 & 34.11 & 0.2345 & 7.6534 & 211 & 3.032 \\
\hline & $\mathrm{Fm} 3 \mathrm{~m}$ & $5.045,5.047^{\mathrm{c}}$ & & & 32.10 & 0.2492 & 6.8820 & 96.59 & 3.714 \\
\hline & P-1 & $4.15,3.57^{\mathrm{d}}$ & 3.57 & $6.6045,3.58^{\mathrm{d}}, 6.426^{\mathrm{d}}$ & 36.42 & 0.2196 & 6.7269 & 78.4 & 3.441 \\
\hline & $\operatorname{Ima} 2$ & $7.191,7.118^{\mathrm{e}}$ & 10.071 & $7.0503,10.072^{\mathrm{e}}, 7.088^{\mathrm{e}}$ & $44.84 ?$ & 0.1784 & 2.27679 & 91.2 & 3.160 \\
\hline & pbca & $5.12,5.12^{\mathrm{f}}$ & 10.51 & $5.267,10.51^{\mathrm{f}}, 5.27^{\mathrm{f}}$ & 32.79 & 0.2439 & 3.3918 & 59.12 & 3.947 \\
\hline & $\mathrm{Pm} 3 \mathrm{~m}$ & 3.945 & & & 61.40 & 0.1302 & 2.4819 & 112.3 & 3.017 \\
\hline $\mathrm{LiNH}_{2}$ & $\mathrm{I}-4$ & $5.0316,5.032^{\mathrm{g}}, 5.017^{\mathrm{h}}$ & $5.097^{\mathrm{i}}$ & $10.069,10.256^{\mathrm{g}}, 10363^{\mathrm{h}}, 10.113^{\mathrm{i}}$ & 112.74 & 0.0709 & 12.0859 & 77.92 & 3.569 \\
\hline
\end{tabular}

${ }^{\mathrm{a}}$ Ref. [18]; ${ }^{\mathrm{b}}$ Ref. [19]; ${ }^{\mathrm{c}}$ Ref. [20]; ${ }^{\mathrm{d}}$ Ref. [21]; ${ }^{\mathrm{e}}$ Ref. [22]; ${ }^{\mathrm{f}}$ Ref. [25]; ${ }^{\mathrm{g}}$ Ref. [27]; ${ }^{\mathrm{h}}$ Ref. [37]; ${ }^{\mathrm{i}}$ Ref. [38]
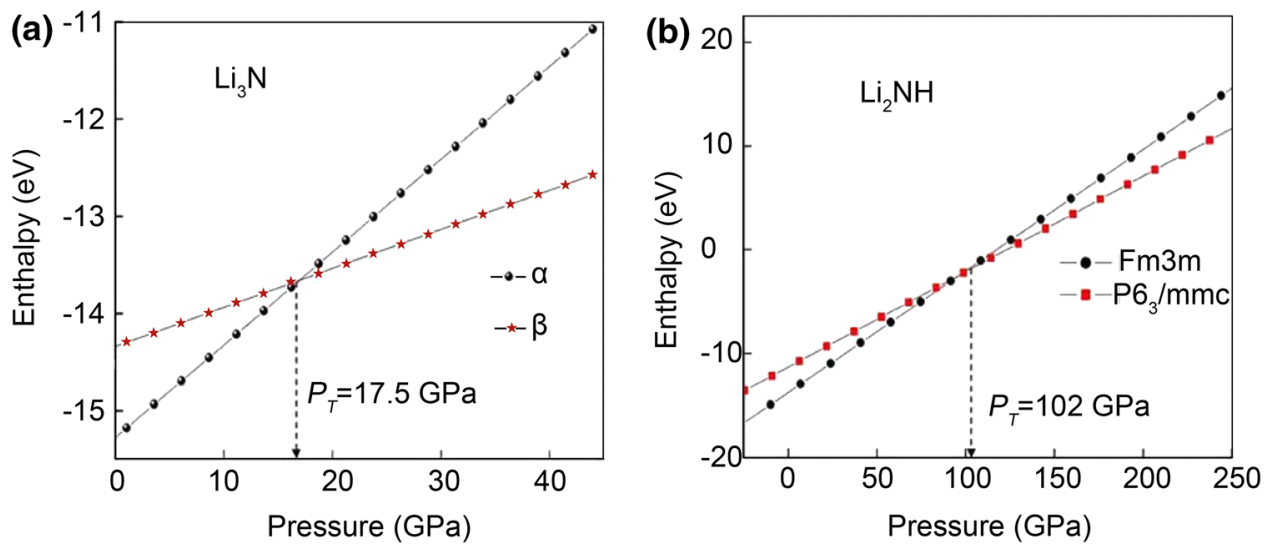

Fig. 1 The enthalpy as a function of pressure: $\mathbf{a} \mathrm{Li}_{3} \mathrm{~N} ; \mathbf{b} \mathrm{Li}_{2} \mathrm{NH}$
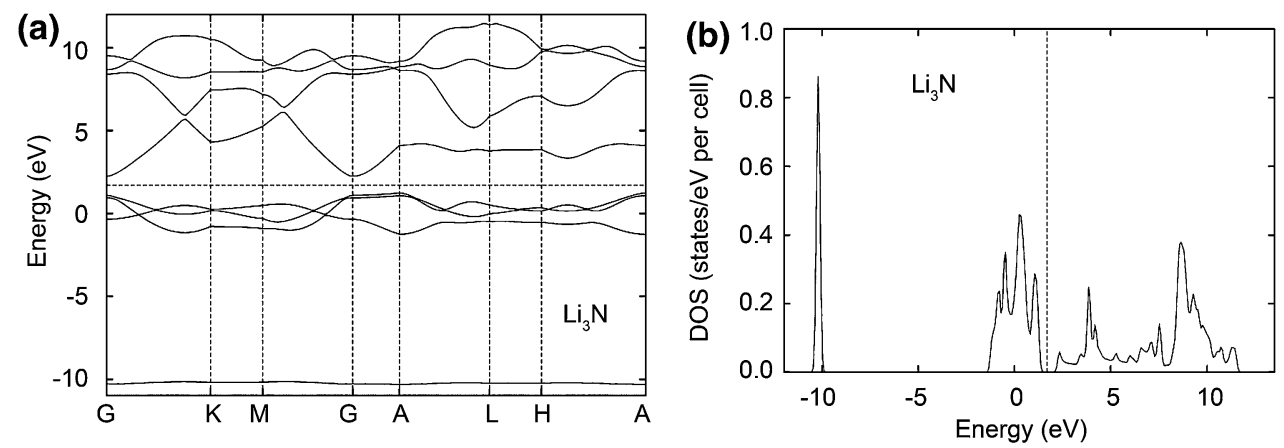

Fig. 2 Electronic structure of $\mathrm{Li}_{3} \mathrm{~N}$ at normal pressure: $\mathbf{a}$ band structure; $\mathbf{b}$ density of states

positioned at the bottom of the valence band, is due to the $\mathrm{N}-2 s$ state. The remaining three bands appearing just below the Fermi level are due to the $s$-state electrons of the $\mathrm{Li}$ and $\mathrm{H}$ atoms and $p$-state electrons of the $\mathrm{N}$ atom, and these valence bands are separated by a wide gap of $8 \mathrm{eV}$ from the bottom most band, indicating the presence of covalent bonding in cubic lithium imide. Near the Fermi level, the band in the energy region $5 \mathrm{eV}$ is due to the large contribution of hydrogen s-state electron with a small contribution from N-2p-state electrons. Hence, hydrogen can be easily released without excess heating, and $\mathrm{Li}_{2} \mathrm{NH}$ can be used as a hydrogen storage material. The empty conduction bands above the Fermi level are due to $s$ and $p$ states of metal and non-metal atoms. At normal pressure, there is no overlapping between the top of the valence band and bottom of the conduction band, which confirms that at 

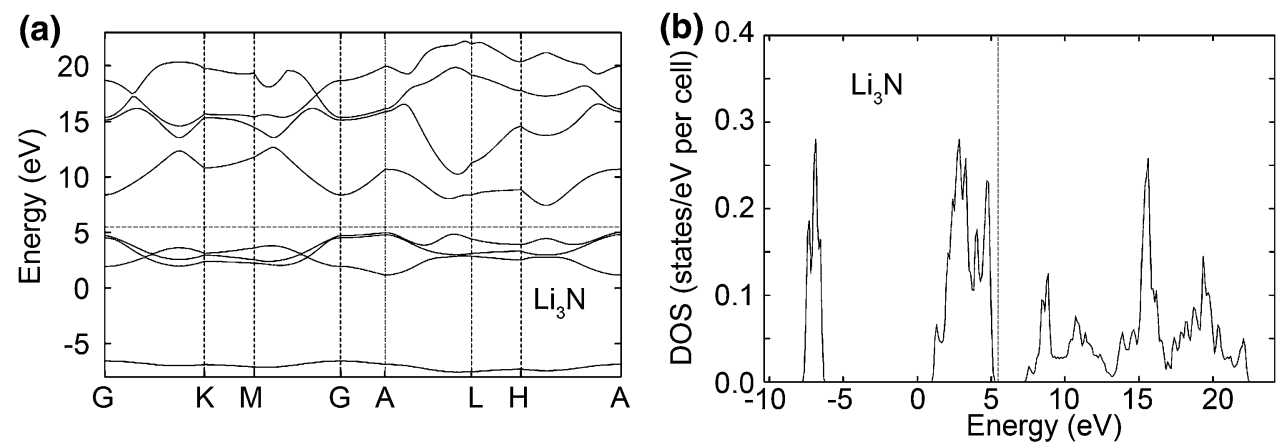

Fig. 3 Electronic structure of $\mathrm{Li}_{3} \mathrm{~N}$ at high pressure: $\mathbf{a}$ band structure; $\mathbf{b}$ density of states
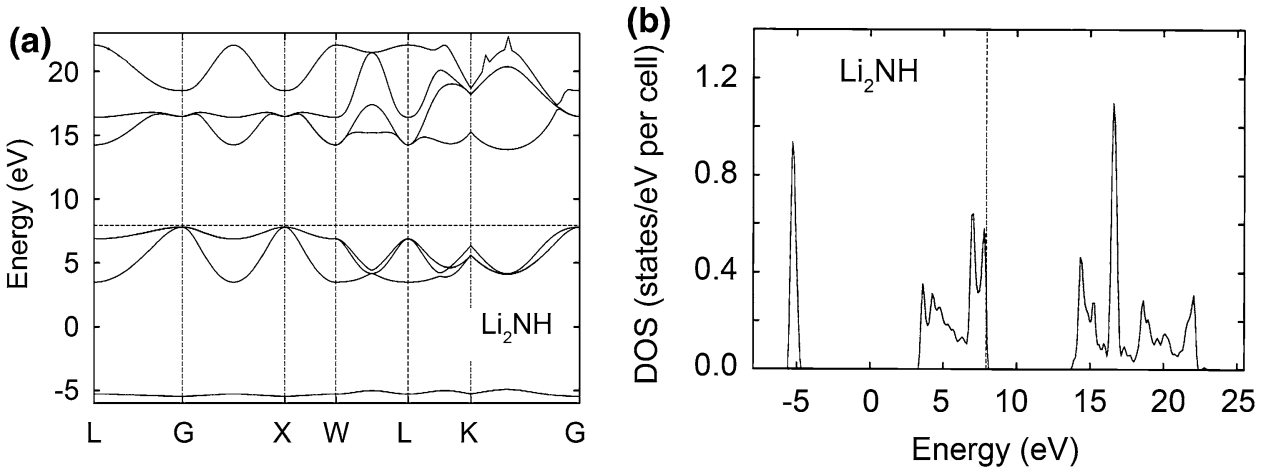

Fig. 4 Electronic structure of $\mathrm{Li}_{2} \mathrm{NH}$ at normal pressure: $\mathbf{a}$ band structure; $\mathbf{b}$ density of states

ambient pressure cubic, lithium imide is an insulator with an energy gap of $4 \mathrm{eV}$. The DOSs of cubic lithium imide at normal pressure is divided into three main regions. The peak in the energy region around $-9 \mathrm{eV}$ is mainly due to the $s$-state electrons of the nitrogen atom. In the region below the Fermi level, the peaks are mainly due to the $p$ state electrons of the nitrogen atom, along with a small contribution from the $s$-state electrons of the lithium and hydrogen atoms. Finally, the conduction states above the Fermi level are due to the mixed $s$ state of $\mathrm{Li}$ and $\mathrm{H}$ atoms and $p$-states $\mathrm{N}$ atom. From the DOSs also, it is inferred that lithium imide is an insulator at normal pressure. The electronic band structure and DOSs for the high pressure stable phase of $\mathrm{Li}_{2} \mathrm{NH}$ (hexagonal phase: space group-P63/ $\mathrm{mmc}$ ) are given in Fig. 5a, b, respectively. It is found that at high pressure, the band gap decreases to $3.84 \mathrm{eV}$ in $\mathrm{Li}_{2} \mathrm{NH}$, which confirms the insulating behavior of $\mathrm{Li}_{2} \mathrm{NH}$.

\subsection{3 $\mathrm{LiNH}_{2}$}

The computed band structure of $\mathrm{LiNH}_{2}$ in tetragonal (I-4) phase along the symmetry directions $\mathrm{Z}-\mathrm{G}-\mathrm{X}-\mathrm{P}-\mathrm{N}$ at ambient condition is given in Fig. 6a. The low lying band at the bottom far from the Fermi level is due to the non-metal
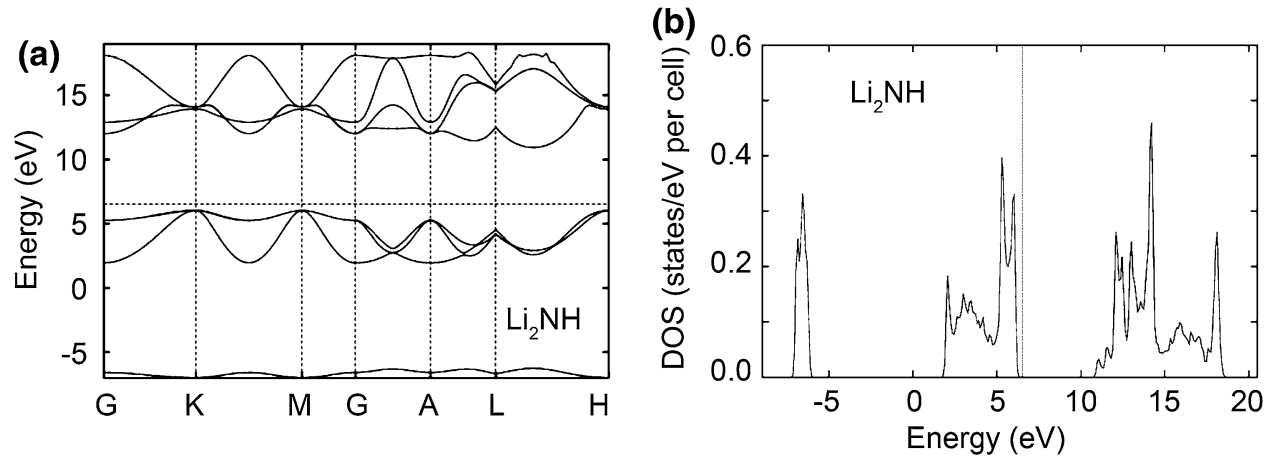

Fig. 5 Electronic structure of $\mathrm{Li}_{2} \mathrm{NH}$ at high pressure: $\mathbf{a}$ band structure; $\mathbf{b}$ density of states 

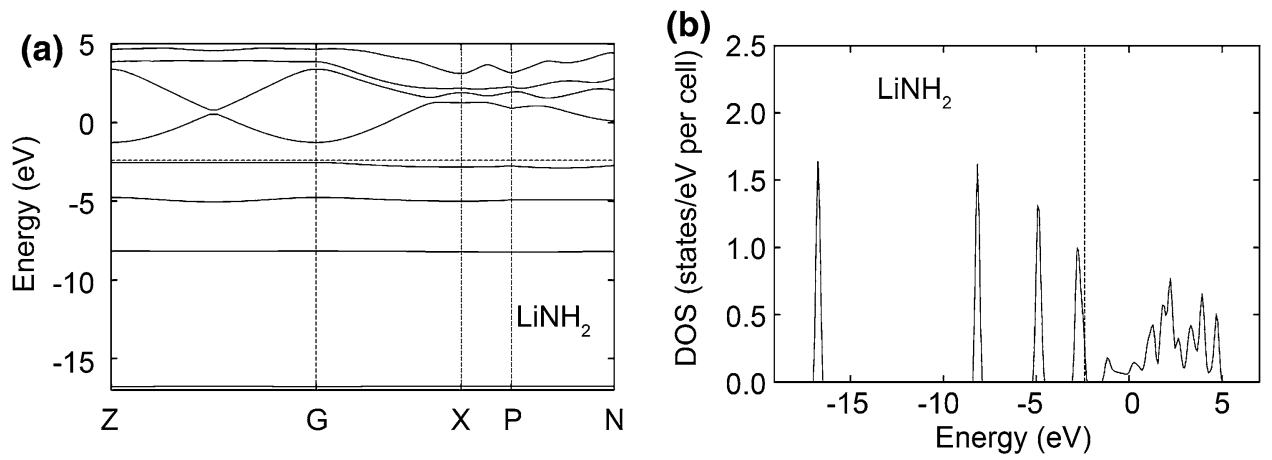

Fig. 6 Electronic structure of $\mathrm{LiNH}_{2}$ at normal pressure: a band structure; b density of states
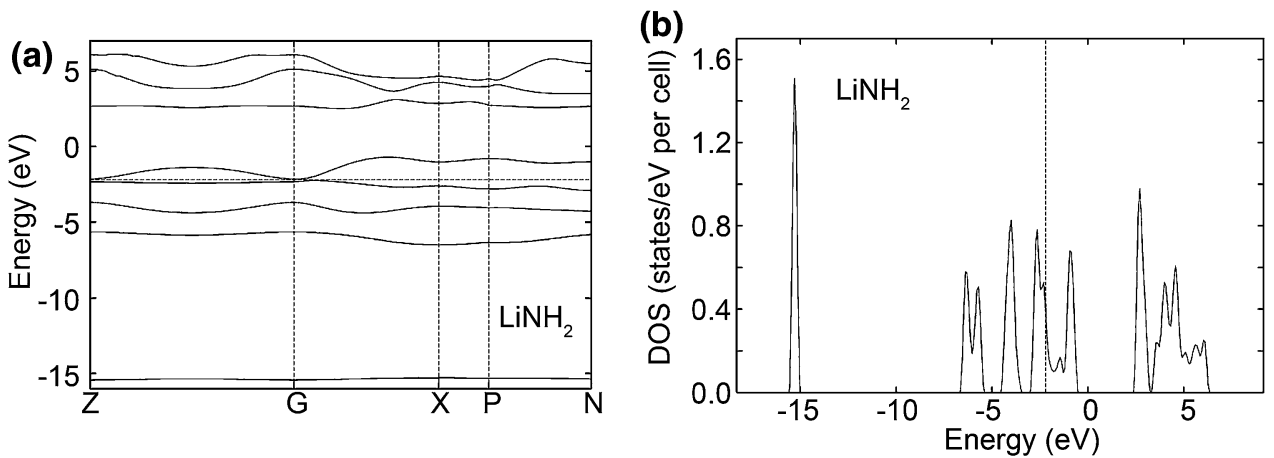

Fig. 7 Electronic structure of $\mathrm{LiNH}_{2}$ at high pressure; a band structure; $\mathbf{b}$ density of states

$\mathrm{N}-2 s$ state. The other bands appearing just below the Fermi level are due to $s$-state electrons of the lithium and hydrogen atom and $p$-state electrons of the nitrogen atom. Since the band formed near the Fermi level is due to the major contribution from hydrogen atom, this material can liberate hydrogen easily and hence used as a hydrogen storage material. These bands are separated from the low lying band by the energy gap of $5 \mathrm{eV}$, which indicates the presence of covalent bonding in tetragonal lithium amide. The conduction bands above the Fermi level are due to $s$ state of $\mathrm{Li}$ and $\mathrm{H}$ atoms and $p$ state of $\mathrm{N}$ atom. The energy band gap between the top of the valence band and bottom of the conduction band is observed to be $1.42 \mathrm{eV}$, which confirms the semiconducting behavior of lithium amide. From the DOSs plot (Fig. 6b), it is seen that the level arising from $\mathrm{N}-2 s$ state gives rise to a longest peak around $-18 \mathrm{eV}$. The peaks just below the Fermi level are due to the $p$-state electrons of the nitrogen atom along with a small contribution from the $s$-state electrons of the $\mathrm{H}$ and $\mathrm{Li}$ atoms. Above the Fermi level, the peaks are due to the mixed $\mathrm{s}$ and $\mathrm{p}$ states of $\mathrm{Li}, \mathrm{N}$ and $\mathrm{H}$ atoms. The semiconducting behavior of $\mathrm{LiNH}_{2}$ at normal pressure is also confirmed from the DOSs plot. The band structure and DOSs are computed for various pressures in tetragonal phase, and it is found that at a pressure of $128 \mathrm{GPa}, \mathrm{LiNH}_{2}$ becomes metal. High pressure band and DOSs plot for tetragonal phase of $\mathrm{LiNH}_{2}$ are given in Fig. 7. It is found that $\mathrm{LiNH}_{2}$ exhibits metallic behavior at a pressure of $128 \mathrm{GPa}$. Thus, a semiconductor to metallic transition is observed at a pressure of $128 \mathrm{GPa}$ in $\mathrm{LiNH}_{2}$.

\subsection{Mechanical Properties}

In order to calculate the elastic constants of a structure, a small strain is applied onto the structure, and its stress is determined. The energy of a strained system [39, 40] can be expressed in terms of the elastic constants $C_{i j}$ as

$$
\begin{aligned}
E\left(V, \varepsilon_{i}\right)= & E\left(V_{0}, 0\right)+V_{0} \sum_{i=1}^{6} \sigma_{i} e_{i}+\frac{V_{0}}{2}\left(\sum_{i, j=1}^{6} C_{i j} e_{i} e_{j}\right) \\
& +O\left(\left\{e_{i}^{3}\right\}\right) \ldots,
\end{aligned}
$$

where $V_{0}$ is the volume of the unstrained lattice, $E_{0}$ is the total minimum energy at this unstrained volume of the crystal, and $V$ is the volume of the lattice due to strain tensor. The elasticity tensor has three independent components $\left(C_{11}, C_{12}, C_{44}\right)$ for cubic crystals, five independent components $\left(C_{11}, C_{12}, C_{44}, C_{13}\right.$ and $\left.C_{33}\right)$ for hexagonal crystals and six independent components $\left(C_{11}, C_{33}, C_{44}\right.$, $C_{66}, C_{12}$ and $C_{13}$ ) for tetragonal crystals. A proper choice 
Table 3 Calculated elastic constants $C_{i j}$ (GPa), Vogit-Reuss-Hill bulk modulus $B$ (GPa), shear modulus $G$ (GPa) and Young's modulus $E$ (GPa), Poission's ratio $v$ and $B / G$ ratio for $\mathrm{Li}_{3} \mathrm{~N}$ with $\mathrm{P} 6 / \mathrm{mmm}$ and $\mathrm{P}_{3} / \mathrm{mmc}$ space groups under different pressure $P$ (GPa)

\begin{tabular}{|c|c|c|c|c|c|c|c|c|c|c|c|}
\hline $\begin{array}{l}\text { Space } \\
\text { group }\end{array}$ & $P$ & $C_{11}$ & $C_{12}$ & $C_{44}$ & $C_{13}$ & $C_{33}$ & $B$ & $G$ & $E$ & $v$ & $B / G$ \\
\hline \multirow[t]{2}{*}{$\begin{array}{l}\mathrm{P} 6 / \\
\mathrm{mmm}\end{array}$} & 0 & $\begin{array}{l}177,165.7^{\mathrm{a}} \\
114^{\mathrm{b}}, 122.8^{\mathrm{c}}\end{array}$ & $\begin{array}{c}28.95,22.7^{\mathrm{a}} \\
38^{\mathrm{b}}, 24.6^{\mathrm{c}}\end{array}$ & $\begin{array}{c}16.27,18.1^{\mathrm{a}} \\
17.0^{\mathrm{b}}, 16.6^{\mathrm{c}}\end{array}$ & $\begin{array}{r}10.01,8.3^{\mathrm{a}}, \\
4.5^{\mathrm{b}}, 5.4^{\mathrm{c}}\end{array}$ & $\begin{array}{l}216,180^{\mathrm{a}}, \\
118^{\mathrm{b}}, 129.5^{\mathrm{c}}\end{array}$ & 74.14 & 63.7 & 162.08 & 0.1868 & 1.163 \\
\hline & 17.5 & 224 & 32 & 18.9 & 11.6 & 225 & 86.98 & 73.89 & 172.75 & 0.1899 & 1.177 \\
\hline \multirow{2}{*}{$\begin{array}{l}\mathrm{P}_{3} / \\
\mathrm{mmc}\end{array}$} & 20 & 237 & 39 & 46.76 & 19.01 & 268 & 99.54 & 89.64 & 206.83 & 0.1737 & 1.110 \\
\hline & 50 & 332 & 51 & 59 & 21.6 & 365 & 135.26 & 115.3 & 269.36 & 0.1890 & 1.173 \\
\hline
\end{tabular}

a Ref. [16]; ${ }^{\mathrm{b}}$ Ref. [9]; ${ }^{\mathrm{c}}$ Ref. [46]

Table 4 Calculated elastic constants $C_{\mathrm{ij}}(\mathrm{GPa})$, Vogit-Reuss-Hill bulk modulus $B$ (GPa), shear modulus $G$ (GPa), Young's modulus $E$ (GPa), Poission's ratio $v$ and $B / G$ ratio for $\mathrm{Li}_{2} \mathrm{NH}$ and $\mathrm{LiNH}_{2}$ under different pressure $P(\mathrm{GPa})$

\begin{tabular}{|c|c|c|c|c|c|c|c|c|c|c|c|c|}
\hline Materials & $P$ & $C_{11}$ & $C_{12}$ & $C_{44}$ & $C_{13}$ & $C_{33}$ & $C_{66}$ & $B$ & $G$ & $E$ & $v$ & $B / G$ \\
\hline \multirow[t]{4}{*}{$\mathrm{Fm} 3 \mathrm{~m} \mathrm{Li}{ }_{2} \mathrm{NH}$} & 0 & 179 & 62 & 90 & & & & 101 & 75.73 & 181.7 & 0.2222 & 1.33 \\
\hline & 13 & 239 & 69 & 116 & & & & 126 & 102.41 & 241.74 & 0.2017 & 1.230 \\
\hline & 62 & 320 & 111 & 120 & & & & 181 & 113.54 & 281.72 & 0.2633 & 1.594 \\
\hline & 102 & 484 & 142 & 149 & & & & 256 & 157.44 & 391.97 & 0.2675 & 1.626 \\
\hline \multirow[t]{2}{*}{$\mathrm{P}_{3} / \mathrm{mmc} \mathrm{Li}_{2} \mathrm{NH}$} & 106 & 545 & 81.2 & 214 & 136 & 763 & & 279.2 & 234.19 & 549.06 & 0.1933 & 1.192 \\
\hline & 244 & 761 & 218 & 264 & 210 & 976 & & 417.0 & 278.99 & 684.35 & 0.2492 & 1.494 \\
\hline I-4 $\mathrm{LiNH}_{2}$ & 0 & 118.2 & 101 & 18.38 & 44.82 & 41.86 & 42.34 & 79.29 & 29.14 & 77.87 & 0.3557 & 2.721 \\
\hline
\end{tabular}

of the set of strains $\left\{e_{i}, i=1,2, \ldots, 6\right\}$ in Eq. (5) leads to a parabolic relationship between $\Delta E / V_{0}\left(\Delta E \equiv E-E_{0}\right)$ and the chosen strain. For each lattice structure of $\mathrm{Li}_{3} \mathrm{~N}$, lithium imide $\left(\mathrm{Li}_{2} \mathrm{NH}\right)$ and lithium amide $\left(\mathrm{LiNH}_{2}\right)$, the lattice was strained by $0, \pm 1$, and $\pm 2 \%$ to obtain their total minimum energies $E(\mathrm{~V})$. These energies and strains were fitted with the corresponding parabolic equations of $\Delta E / V_{0}$ to yield the required second-order elastic constants [41]. While computing these energies, all atoms are allowed to relax with the cell shape and volume fixed by the choice of strains $\left\{e_{i}\right\}$. From the calculated $C_{i j}$ values, the bulk modulus and shear modulus for the cubic, hexagonal and tetragonal crystals are determined using the Voigt-Reuss-Hill averaging scheme [42-44].

The Born-Huang elastic stability criteria [45] for the cubic crystals are

$C_{44}>0, C_{11}>\left|C_{12}\right|, C_{11}+2 C_{12}>0$,

for hexagonal phase

$C_{44}>0, C_{11}>C_{12},\left(C_{11}+2 C_{12}\right) C_{33}>2 C_{13}^{2}$,

and for tetragonal phase

$$
\begin{aligned}
C_{11}>0, C_{33} & >0, C_{44}>0, C_{66}>0,\left(C_{11}-2 C_{12}\right)>0, \\
\left(C_{11}+C_{33}-2 C_{13}\right) & >0,\left[2\left(C_{11}+2 C_{12}\right)+C_{33}+4 C_{13}\right]>0 .
\end{aligned}
$$

The mechanical properties for $\mathrm{Li}_{3} \mathrm{~N}, \mathrm{Li}_{2} \mathrm{NH}$ and $\mathrm{LiNH}_{2}$ with considered structures are presented in Tables 3 and 4 along with the available data [9, 16, 46]. Clearly, the calculated elastic constants for $\mathrm{Li}_{3} \mathrm{~N}$ and $\mathrm{Li}_{2} \mathrm{NH}$ under normal and high pressure and $\mathrm{LiNH}_{2}$ at normal pressure satisfy Born-Huang criteria, suggesting that they are mechanically stable. Bulk modulus $\left(B_{0}\right)$ and shear modulus $(G)$ can measure the resistance of a material to volume and shape change, respectively. The results in Tables 3 and 4 indicate that $\mathrm{Li}_{3} \mathrm{~N}, \mathrm{Li}_{2} \mathrm{NH}$ and $\mathrm{LiNH}_{2}$ have seemed more inclined to resist with volume change than shape change. Young's modulus is often used to provide a measure of stiffness of a solid, i.e., larger the value of Young's modulus, stiffer is the material. It is found that $\mathrm{Li}_{2} \mathrm{NH}$ is the stiffest among the considered materials. In addition, Poisson's ratio provides more information about the characteristics of the bonding forces than any of the other elastic constants. The ratio of bulk modulus to shear modulus is used to estimate the brittle or ductile behavior of materials. A high $B / G$ ratio is associated with ductility, while a low $B / G$ ratio corresponds to brittle nature. The critical value which separates ductile and brittle materials is about 1.75. The calculated values of $B / G$ ratio predict that the $\mathrm{Li}_{3} \mathrm{~N}, \mathrm{Li}_{2} \mathrm{NH}$ and $\mathrm{LiNH}_{2}$ are brittle in nature.

The variations of elastic moduli with pressure for $\mathrm{Li}_{3} \mathrm{~N}$ and $\mathrm{Li}_{2} \mathrm{NH}$ are shown in Figs. 8 and 9. It is observed that 


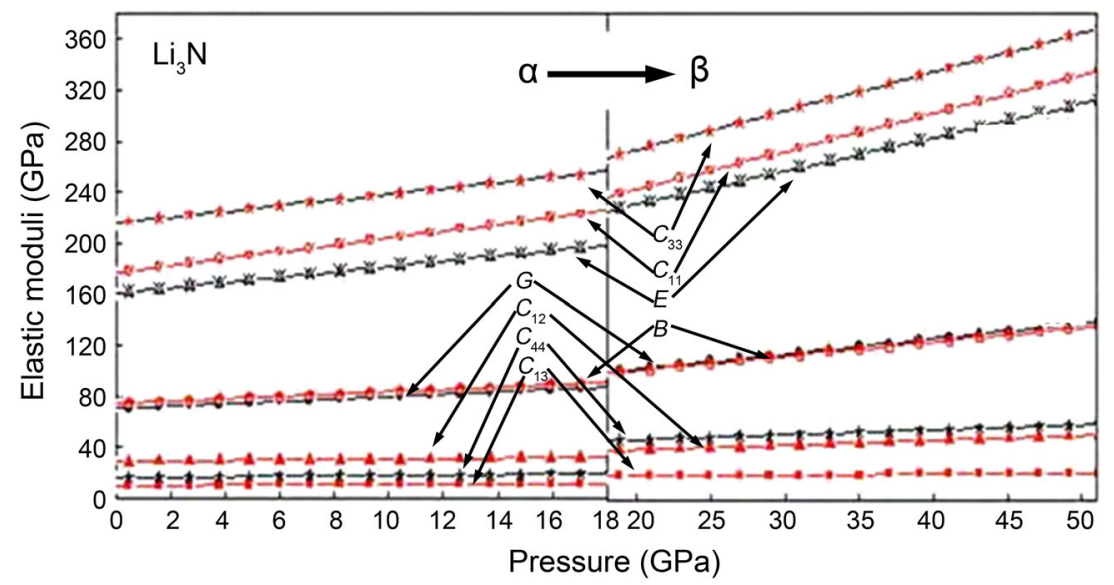

Fig. 8 Pressure dependence of elastic moduli of $\mathrm{Li}_{3} \mathrm{~N}$

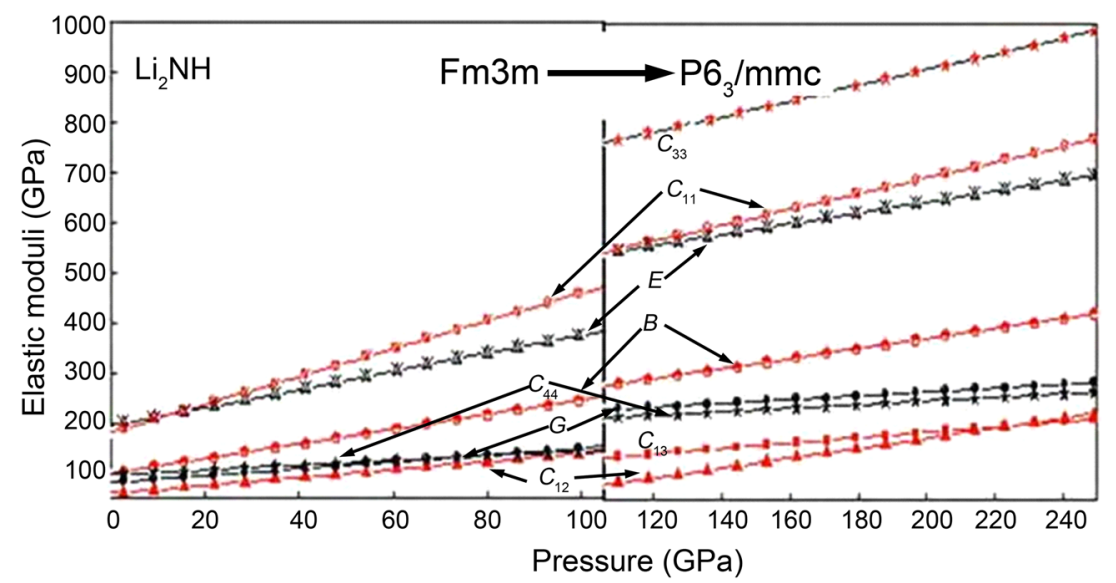

Fig. 9 Pressure dependence of elastic moduli of $\mathrm{Li}_{2} \mathrm{NH}$

all the elastic constants increase monotonically with pressure. There is a dip in the variation of elastic moduli at the transition pressure. The elastic constants $C_{11}$ and $C_{33}$ show a drastic increase with pressure, whereas other constants show moderate increase.

\subsection{Hydrogen Storage in $\mathrm{Li}_{3} \mathrm{~N}, \mathrm{Li}_{2} \mathrm{NH}$ and $\mathrm{LiNH}_{2}$}

Hydrogen fuel, which can be readily produced from renewable energy sources, contains at least three times larger chemical energy per mass $142 \mathrm{MJ} / \mathrm{kg}$ than any chemical fuel, thus making a hydrogen fuel cell an attractive alternative to the internal combustion engine for transportation [47]. Elements, especially those in group I-IV and some transition metals, have their hydride and amidelimides forms. The density of $\mathrm{H}$ per unit cell of $\mathrm{Li}_{2} \mathrm{NH}$ and $\mathrm{LiNH}_{2}$ is 0.0521 and $0.0262 \mathrm{~g} / \mathrm{cm}^{3}$. The storage capacity of $\mathrm{Li}_{2} \mathrm{NH}$ and $\mathrm{LiNH}_{2}$ is 3.49 and 8.77. It is seen that the weight percentage of hydrogen is higher in $\mathrm{LiNH}_{2}$ compared to $\mathrm{Li}_{2} \mathrm{NH}$.

\section{Conclusions}

The structural, electronic and mechanical properties of lithium nitride $\left(\mathrm{Li}_{3} \mathrm{~N}\right)$, lithium imide $\left(\mathrm{Li}_{2} \mathrm{NH}\right)$ and lithium amide $\left(\mathrm{LiNH}_{2}\right)$ have been investigated. The results suggest that $\mathrm{Li}_{3} \mathrm{~N}, \mathrm{Li}_{2} \mathrm{NH}$ and $\mathrm{LiNH}_{2}$ are crystallized in $\alpha$-phase, cubic (Fm-3m) phase and tetragonal (I-4) phase, respectively, at normal pressure. The pressure-induced structural phase transitions from $\alpha-\mathrm{P} 6 / \mathrm{mmm}$ to $\beta-\mathrm{P} 6_{3} / \mathrm{mmc}$ phase at a pressure of $17.5 \mathrm{GPa}$ in $\mathrm{Li}_{3} \mathrm{~N}$ and cubic-Fm3m to hexagonal-P $6_{3} / \mathrm{mmc}$ phase transition at a pressure of $102 \mathrm{GPa}$ in $\mathrm{Li}_{2} \mathrm{NH}$ are observed. A new high pressure hexagonal$\mathrm{P}_{3} / \mathrm{mmc}$ phase is predicted for $\mathrm{Li}_{2} \mathrm{NH}$. Electronic structure reveals that both $\mathrm{Li}_{3} \mathrm{~N}$ and $\mathrm{Li}_{2} \mathrm{NH}$ are non-metallic in nature at normal and under high pressure, whereas in $\mathrm{LiNH}_{2}$ semiconductor to metallic transition is predicted at a pressure of $128 \mathrm{GPa}$. All the calculated elastic constants obey the Born-Huang criteria, suggesting that they are mechanically stable at normal pressure. It is observed that 
pressure has an important influence on elastic constants, Young's modulus, bulk modulus and shear modulus.

Acknowledgments The financial assistance from UGC under research award scheme (No. F: 30-36/2011 SA-II), India, is duly acknowledged with gratitude.

\section{References}

[1] A. Rabenau, Adv. Solid State Phys. 18, 77 (1978)

[2] P. Chen, Z. Ziong, J. Luo, J. Lin, K. Lee, Tan. Nature (London) 420, 302 (2002)

[3] T. Ichikawa, S. Isobe, N. Hanada, H. Fujii, J. Alloys Compd. 365, 271 (2004)

[4] Y.H. Hu, E. Ruckenstein, Ind. Eng. Chem. Res. 44, 1510 (2005)

[5] Y. Nakamori, G. Kitahara, K. Miwa, S. Towata, S. Orima, Appl. Phys. A 80, 1 (2005)

[6] Y. Xie, Y. Qian, W. Wang, S. Zhang, Y. Zhang, Science 272, 1926 (1996)

[7] Y. Yan, J.Y. Zhang, T. Cui, Y. Li, Y.M. Ma, G.T. Zou, Eur. Phys. J. B 61, 397 (2008)

[8] A. Rabenau, H. Schulz, J. Less Common Met. 50, 155 (1976)

[9] W. Kress, H. Grimm, W. Press, J. Lefebvre, Phys. Rev. B 22, 4620 (1980)

[10] H.R. Chandrasekhar, G. Bhattacharya, R. Migoni, H. Bilz, Phys. Rev B 30, 972 (1984)

[11] J. Sarnthein, K. Schwarz, P.E. Blochl, Phys. Rev. B 53, 9084 (1996)

[12] R. Dovesi, C. Pisani, F. Ricca, C. Roetti, V.R. Saunders, Phys. Rev. B 30, 972 (1984)

[13] M. Mali, J. Roos, D. Brinkmann, Phys. Rev. B 36, 3888 (1987)

[14] A.C. Ho, M.K. Granger, A.L. Ruoff, P.E. Van Camp, V.E. Van Doren, Phys. Rev. B 59, 6083 (1999)

[15] A. Lazicki, B. Maddox, W.J. Evans, C.S. Yoo, A.K. McMahan, W.E. Pickett, P. Chow, Phys. Rev. Lett. 95, 165503 (2005)

[16] A. Hossain, A.K.M.S. Islam, F.N. Islam, J. Sci. Res. 1, 182 (2009)

[17] P. Chen, Z. Xiang, J. Luo, J. Lin, K.L. Tan, J. Phys. Chem. B 107, 10967 (2003)

[18] K. Ohoyama, Y. Nakamori, S. Orimo, K. Yamada, J. Phys. Soc. Jpn. 74, 483 (2005)
[19] B. Magyari-Kope, V. Ozolins, C. Wolveron, Phys. Rev. B 73, 220101 (2006)

[20] T. Noritake, H. Nozaki, M. Aoki, S. Towata, G. Hitahara, Y. Nakamori, S. Orimo, J. Alloys Compd. 393, 264 (2005)

[21] T. Mueller, G. Ceder, Phys. Rev. B 74, 134104 (2006)

[22] T. Tsumuraya, T. Shishidou, T. Oguchi, J. Alloys Compd. 446, 323 (2007)

[23] C. Wolverton, D.J. Siegel, A.R. Akbarzadeh, V. Ozolins, J. Phys. Condens. Matter 20, 064228 (2008)

[24] J.C. Crivello, M. Gupta, R. Ceny, M. Latroche, D. Chandra, Phys. Rev. B 81, 104113 (2010)

[25] K. Miwa, N. Ohba, S.I. Towata, Phys. Rev. B 71, 195109 (2005)

[26] J.F. Herbst, L.G. Hector Jr., Phys. Rev. B 72, 125120 (2005)

[27] G.L. Lin, G.Y. Zhang, H. Zhang, S.L. Zhu, Chin. Phy. B 20, 038801 (2011)

[28] J. Perdew, J.A. Chevary, S.H. Vosko, K.A. Jacjson, M.R. Pederson, D.J. Singh, C. Filolhais, Phys. Rev. B 46, 6671 (1992)

[29] G. Kresse, D. Joubert, Phys. Rev. B 59, 1758 (1999)

[30] G. Kresse, J. Hafner, Phys. Rev. B 47, 558 (1993)

[31] G. Kresse, J. Furthmuller, Comput. Mater. Sci. 6, 15 (1996)

[32] P.E. Blochl, Phys. Rev. B 50, 17953 (1994)

[33] J.P. Perdew, K. Burke, M. Ernzerhof, Phys. Rev. Lett. 78, 1396 (1997)

[34] H.J. Monkhorst, J.D. Pack, Phys. Rev. B 13, 5188 (1976)

[35] F. Birch, Phys. Rev. 71, 809 (1947)

[36] H.J. Beister, Chem. Int. Ed. Engl. 27, 1101 (1998)

[37] W. Luo, J. Alloys Compd. 385, 316 (2004)

[38] M. Sorby, Y. Nakamura, H.W. Brinks, T. Ichikawa, S. Hino, H. Fujii, B.C. Hauback, J. Alloys Compd. 428, 297 (2007)

[39] J.F. Nye, Physical Properties of Crystals (Oxford University Press, Oxford, 1957)

[40] S.Q. Wu, Z.F. Hou, Z.Z. Zhu, Solid State Commun. 143, 425 (2007)

[41] M. Kalay, H.H. Kart, T. Çagin, J. Alloys Compd. 484, 431 (2009)

[42] W. Voigt, Lehrbuch der Kristallphysik: Terubner-Leipzig (Macmillan, New York, 1928)

[43] A. Reuss, Z. Angew, Math. Mech. 9, 49 (1929)

[44] R. Hill, Proc. Phys. Soc. Lond. A 65, 349 (1952)

[45] M. Born, K. Huang, Dynamical Theory of Crystal Lattices (Clarendon Press, Oxford, 1956)

[46] S.J. Clark, M.D. Segal, C.J. Pickard, P.J. Hasnip, M.J. Probert, K. Refson, M.C. Payne, Z. Kristall. 220, 567 (2005)

[47] L. Schlapbach, A. Zuttel, Nature 414(6861), 353 (2001) 